ORIGIN OF ORGANIC NATTER IN EARLY SOLAR SYSTEH. I.

HYDROCARBONS

Martin H. Studier, Ryoichi Hayatsu

Edward Anders

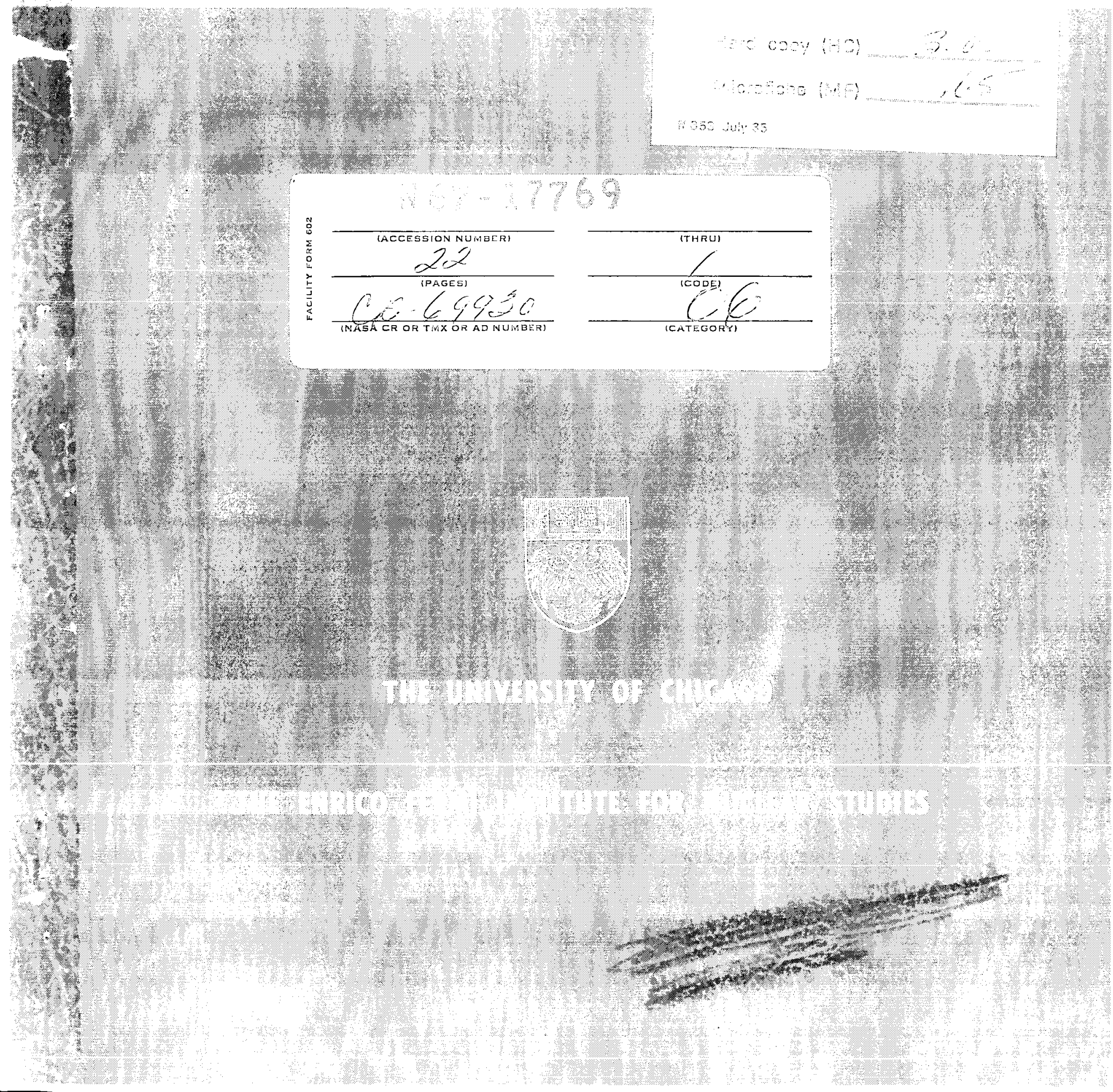




\title{
ORIGIN OF ORGANIC MATTER IN EARLY SOLAR SYSTEM. I HYDROCARBONS
}

\author{
Martin H. Studier \\ Chemistry Division, \\ Argonne National Laboratory, \\ Argonne, Illinois \\ Ryoichi Hayatsu and Edward Anders \\ Enrico Fermi Institute \\ University of Chicago, Chicago, Illinois
}

\begin{abstract}
Submitted to
\end{abstract}
Science

December 1965

NASA Grant NsG-366 Research

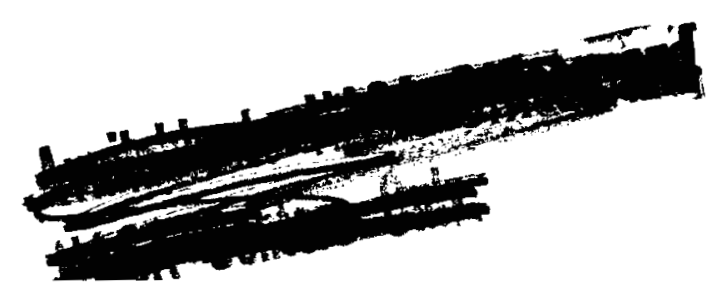




$$
167-17769
$$

Iron and stony meteorites are effective catalysts for a Fischer-Tropsch type reaction between carbon monoxide and hydrogen. Even in hydrogen-rich mixtures approaching cosmic composition, aliphatic and aromatic hydrocarbons are produced rapidly at temperatures between $25^{\circ} \mathrm{C}$ and $580^{\circ} \mathrm{C}$. When these hydrocarbons are partially equilibrated by sustained reheating, they match the hydrocarbon distribution in carbonaceous chondrites in all important respects. 
In an earlier paper (1), we reported two striking properties of the trapped volatiles in carbonaceous chondrites: methane was at least 1000 times more abundant than ethane, and aromatic hydrocarbons predominated over aliphatic ones. The observed distribution grossly resembled an equilibrium distribution in a carbon-rich $\mathrm{C}-\mathrm{H}-\mathrm{O}$ mixture (2). We therefore proposed that the organic compounds in meteorites formed in the solar nebula under near-equilibrium conditions, during rapid cooling of a gas phase depleted in hydrogen. We have now attempted to test this hypothesis experimentally.

For our experiments we used mixtures of $\mathrm{CO}$ and $\mathrm{H}_{2}$. The choice of CO was obvious: at temperatures of $1000-2000^{\circ} \mathrm{C}$ and moderate pressures, $C O$ is the dominant form of carbon in a cosmic gas (3). The composition of the gas mixture ranged from an (atomic) $\mathrm{C}: \mathrm{H}: \mathrm{O}$ ratio of $1: 1: 1$, well within the "asphalt" region of the $\mathrm{C}-\mathrm{H}-\mathrm{O}$ phase diagram (2), to $1: 500: 1$, close to the cosmic value. Elemental carbon is the stable equilibrium product in the asphalt region, but if its formation is kinetically inhibited, large amounts of aromatic hydrocarbons can form instead as metastable products (2). Our entire hypothesis hinged on the assumption that the formation of free carbon would be inhibited long enough to allow the buildup of a metastable distribution rich in aromatics. Our experiments were to test this assumption. 
In order to keep the system simple, we limited our first series of experiments to $\mathrm{C}-\mathrm{H}-\mathrm{O}$ mixtures, excluding other nonmetallic constituents of a cosmic gas. However, it is known that silicate and metal particles condense when a cosmic gas cools from high temperatures (4). Such particles might catalyze reactions of $\mathrm{CO}$ and other carbon compounds. We therefore added to some of our gas mixtures $0.01-0.1 \mathrm{~g}$ of coarsely ground meteorite powder, normally iron (Canyon Diablo) but in one case, stone (Bruderheim). Before use, the meteorite powder was baked out overnight at $600-900^{\circ} \mathrm{C}$ until all organics had been removed.

The gas mixture, usually at a total pressure of 1-2 atm at room temperature, was placed in a $45 \mathrm{~cm} \times 1 \mathrm{~cm} \mathrm{I.} \mathrm{D.} \mathrm{quartz}$ tube sealed at one end and joined to a metal valve by a graded seal. The sealed end was inserted to a depth of $7 \mathrm{~cm}$ in a tubular furnace which was heated to the desired temperature. The other end remained at room temperature. In this arrangement, volatile compounds could distill away from the reaction zone, thus remaining protected to some extent from iurther reaction. The gas phase was examined periodically on a time-of-flight mass spectrometer, as described in (1).

It soon became apparent that meteorite powder had a strong catalytic effect. Without meteorite, the gas mixture had to be heated for a long time to produce detectable amounts of organics. 
With Canyon Diablo powder, complex hydrocarbons were produced rapidly and in great variety: all n-paraffins from $\mathrm{CH}_{4}$ to $\mathrm{C}_{20} \mathrm{H}_{42}$ and beyond; methyl alkanes; cycloalkanes; aromatics; alkylaromatics (Fig. 1). Not a trace of free carbon was seen.

Evidently, the $\mathrm{CO}$ and $\mathrm{H}_{2}$ had merely reacted according to the familiar Fischer-Tropsch reaction which produces hydrocarbons via oxygenated intermediates:

$$
\mathrm{nCO}+(\mathrm{n}+0.5 \mathrm{x}) \mathrm{H}_{2}+\mathrm{C}_{\mathrm{n}} \mathrm{H}_{\mathrm{x}}+\mathrm{nH}_{2} \mathrm{O}
$$

In the industrial Fischer-Tropsch synthesis, $\mathrm{Fe}$, Co, and $\mathrm{Ni}$ are used as catalysts. It so happens that meteoritic iron consists largely of these three elements, and thus is an effective catalyst for this reaction.

During the reaction, the meteorite was partly converted to the volatile carbonyls $\mathrm{Fe}(\mathrm{CO})_{5}$ and $\mathrm{Ni}(\mathrm{CO})_{4}$. The remainder was gradually oxidized to $\mathrm{Fe}_{3} \mathrm{O}_{4}$ impregnated with relatively nonvolatile hydrocarbons. $\mathrm{Fe}_{3} \mathrm{O}_{4}$ itself is an effective FischerTropsch catalyst (6). Depending on the degree of oxidation, these reactions consumed some fraction of the oxygen of the system, generally no more than $10-20 \%$.

Quite obviously, the reaction did not proceed to equilibrium at these low temperatures. For a mixture lying in the "asphalt" region of the $\mathrm{C}-\mathrm{H}-\mathrm{O}$ diagram, only trace amounts of aliphatics 
heavier than methane were expected under equilibrium conditions. Instead, aliphatics often predominated over aromatics in our reaction mixtures. Apparently the product distribution was governed by steric and kinetic factors, rather than by thermodynamic ones. This was shown most strikingly in a 69-hr experiment at $200^{\circ} \mathrm{C}$, where the $\mathrm{C}: \mathrm{H}: \mathrm{O}$ ration was $1: 500: 1$, far outside the asphalt region but close to the cosmic value. Under equilibrium conditions, methane and $\mathrm{CO}_{2}$ should have been the principal products, with mere traces of higher aliphatics. Aromatics should have formed at levels of $<10^{-20}$ moles per mole of total carbon (2). Yet this experiment again gave small amounts of benzene: and toluene, with larger amounts of various aliphatic products, including keto compounds from $\mathrm{C}_{3}$ to $\mathrm{C}_{9}$.

In all our experiments, the product distribution was strongly dependent on time and temperature. Higher temperatures and longer times resulted in a closer approach to equilibrium. In one experiment a $1: 1$ mixture of $\mathrm{CO}$ and $\mathrm{H}_{2}$ at a total pressure of $2 \mathrm{~atm}$ was heated stepwise from room temperature to $580^{\circ} \mathrm{C}$ in the presence of Cañyon Diablo powder. The following changes were observed.

1. After two hours at room temperature methane, ethane, dimethyl ether, and a trace of toluene were observed. No benzene was seen.

2. After 30 minutes at $100^{\circ} \mathrm{C}$, aliphatic hydrocarbons $\mathrm{C}_{1}-\mathrm{C}_{5}$ were seen along with a trace of benzene. Toluene 
seemed slightly more abundant. All these products were somewhat enhanced after an additional 2 hours at $115^{\circ} \mathrm{C}, \mathrm{C}_{6}$ appeared also.

3. After another 1.8 hours at $115^{\circ} \mathrm{C}$ prominent peaks which may have been due to 1,4 dioxane appeared at masses 88 and 58. Toluene was more abundant but benzene was present in traces only. Some xylene appeared to be present. Methane and dimethyl ether were much more abundant.

4. After 16 hours at $230^{\circ} \mathrm{C}$ the complexity of the spectrum had increased markedly. Oxygenated aliphatic compounds to mass 128 seemed to be present. Toluene, xylene, and benzene were more abundant, but dimethyl ether and dioxane had diminished.

5. After an hour at $350^{\circ} \mathrm{C}$ ethylene and butene were observed. Dimethyl ether had further decreased.

6. After two hours at $460^{\circ} \mathrm{C}$ aromatic compounds were noticeably more abundant. Oxygenated aliphatic compounds to mass 170 were observed.

7. After 68 hours at $580^{\circ} \mathrm{C}$ most of the $\mathrm{CO}$ and $\mathrm{H}_{2}$ had disappeared. There remained large amounts of methane, water, carbon dioxide, and benzene, with lesser amounts of other aromatic compounds including toluene, xylene, indene, naphthalene, methyl and dimethyl naphthalene, and biphenyl. Except for methane the aliphatic compounds had disappeared. The ratio of benzene to toluene was much larger than at lower temperatures. Apparently the mixture now was close to equilibrium. Both the high methane/ethane ratio and the predominance of aromatics are 
characteristic of equilibrium in the "asphalt region" of the C-H-O diagram (2). Again, not a trace of free carbon was seen.

At still higher temperatures, equilibrium was approached rapidly. Once methane had formed, a distribution rich in polynuclear aromatics was obtained, regardless of whether catalyst was present or not. (That aromatics form in the pyrolysis of methane had been known since the 19th century [7]). Results of typical $900^{\circ} \mathrm{C}$ experiments are shown in Fig 2 .

In these experiments, the lighter aromatics were identified by mass spectrometry, as usual. Owing to their low volatility, compounds of 5 or more aromatic rings were not sought in the gas phase, but were recovered in solvent rinsings of the reaction tube. They were separated by chromatography on a $92 \mathrm{~mm} \mathbf{x}$ $7 \mathrm{~mm}$ alumina column, and identified by UV spectrophotometry. In some cases additional separations and identifications were carried out via picrates. In the $900^{\circ}$ experiment illustrated in Fig. 2, $15 \mathrm{mg}$ of 4-7 ring aromatics was recovered, corresponding to about $35 \%$ of the total carbon in the system. Ihis was the only experiment in which some free carbon formed.

At longer times, aromatic-rich distributions were obtained even at temperatures much below $900^{\circ} \mathrm{C}$. A mixture of CO (1 atm) and $\mathrm{H}_{2}$ (2 atm) heated with Canyon Diablo to $300^{\circ} \mathrm{C}$ for $112 \mathrm{hrs}$ gave $\mathrm{CH}_{4}, \mathrm{CO}_{2}, \mathrm{H}_{2} \mathrm{O}$, and large amounts of aromatics including 
many polynuclear compounds, with only traces of aliphatics heavier than methane. A parallel experiment at $250^{\circ} \mathrm{C}$ gave a nearly complementary distribution: aliphatics to mass 400 and beyond, with only minor amounts of aromatics. No free carbon was seen in either experiment.

In general, the proportions of aliphatics, aromatics, and alicyclics could be varied within wide limits by proper choice of composition, temperature, pressure, and time. A further degree of freedom was provided by the choice of catalyst. Conventional Fischer-Tropsch catalysts ( $\mathrm{Fe}, \mathrm{Co}$ ) give only traces of aromatics, but others (e.g. $\mathrm{Al}_{2} \mathrm{O}_{3}, \mathrm{ZnS}, \mathrm{Cr}_{2} \mathrm{O}_{3}$, etc.) yield aromatics preferentially (8). Some differences in product distribution were also observed in our experiments when stony meteorite was substituted for Canyon Diablo iron.

On sustained reheating, all mixtures lying above the asphalt threshold of the $\mathrm{C}-\mathrm{H}-\mathrm{O}$ diagram tended to converge to the same equilibrium state. Methane and aromatics were enhanced at the expense of aliphatics, presumably by disproportionation reactions of the type:

$$
23 \mathrm{C}_{2} \mathrm{H}_{6} \rightarrow 32 \mathrm{CH}_{4}+\mathrm{C}_{14} \mathrm{H}_{10}
$$

Similar reactions apparently take place spontaneously in nature, when (aliphatic) plant materials are converted to (aromatic) coal. Methane, the expected byproduct of this 
reaction, is often associated with coal deposits.

Now we can attempt to reinterpret the meteorite data in the light of our experimental results. The meteoritic hydrocarbon distribution has the following main characteristics:

1. The methane/ethane ratio is greater than 1000. The next three alkanes, from $\mathrm{C}_{3}$ to $\mathrm{C}_{5}$ are undetectable (1). 2. Hydrocarbons from $\mathrm{C}_{6}$ to at least $\mathrm{C}_{10}$ are represented almost entirely by aromatics, not aliphatics (1).

3. At higher carbon numbers, aromatics still predominate. If the insoluble aromatic polymer is included, aromatics comprise about 1000-5000 ppm, compared to only 10-100 ppm of aliphatics $(9,10)$.

4. Among heavier aliphatics, n-alkanes are prominent, comprising perhaps one-tenth of the total paraffin fraction. Contrary to earlier reports (11), they do not seem to show an odd-carbon preference (10).

5. Polynuclear aromatics of up to 6 rings are present (12). 6. Isoprenoid alkanes are present in both carbonaceous (10) and non-carbonaceous chondrites (13). 7. Free carbon is absent (14). The first two observations are based on traces of volatiles 
trapped at highly retentive sites inside mineral grains (1). They alone reflect the original distribution. The last five pertain to relatively nonvolatile organics which, having been situated at less retentive, interstitial and surface sites, apparently lost their complement of volatiles.

Observations $1,2,3,5$, and 7 led us to propose that the meteorite organics formed under near-equilibrium conditions (1). However, the presence of even small amounts of alkanes was an embarrassment to the equilibrium hypothesis. Under equilibrium conditions, these compounds should be some $10^{-20}$ times less abundant than the aromatics (2), but their actual abundance is closer to $10^{-2}$. To make matters worse, straight-chain isomers predominate among the alkanes, so that a highly selective formation mechanism is called for. In our earlier paper we had suggested several such mechanisms, including "metastable formation in a partially equilibrated mixture" (1), while Oró (15) had explicitly proposed the Fischer-Tropsch reaction. The present work indeed supports these suggestions.

Our experiments show that a partially equilibrated FischerTropsch distribution matches the meteorite distribution in all: its principal features. Two steps are required to produce such a distribution: a primary Fischer-Tropsch reaction with meteoritic catalyst which yields n-alkanes and light aromatics (observations 4 and 2 ); and a secondary, partial 
equilibration that depletes lighter alkanes, enhances aromatics and methane, and produces polynuclear aromatics but no free carbon (observations $1,3,5,7$ ). This leaves only the isoprenoid hydrocarbons (obs. 6) to be accounted for, whose presence in meteorites had not been established when our previous paper was written. These compounds have not been previously reported from Fischer-Tropsch syntheses. However, we detected them in several experiments by a combination of gas chromatography and mass spectrometry. Their presence is not surprising since the alkadienes formed in our experiments (Fig. 1) are known to polymerize and isomerize readily to isoprenoid hydrocarbons (16). The identification of isoprenoid hydrocarbons will be described in detail in another paper of this series.

As far as can be told at present, the Fischer-Tropsch reaction seems capable of accounting not only for the gross features of the meteoritic distribution, but also for its finer details. Lovelock (17) has pointed out that hydrocarbons from both the Murray meteorite and the Fischer-Tropsch reaction show a "random" distribution, in contrast to the "ordered" distributions of biogenic hydrocarbons.

This two-step model also eliminates the restriction that the gas phase from which the meteorite organics formed be depleted in hydrogen. As our experiments show, the first 
(Fischer-Tropsch) step proceeds readily at $\mathrm{H} / \mathrm{C}$ ratios as high as 500 , close to the cosmic value. Only in the second (equilibration) step is it necessary that the composition lie in the asphalt region $(\mathrm{H} / \mathrm{C}<4)$. But the organics made in the primary step have $\mathrm{H} / \mathrm{C} \leq 2$ and $0 / \mathrm{C}<1$. This composition automatically places them in the asphalt region, once they condense and thus become chemically or physically isolated from the hydrogenrich gas phase.

The time and temperature conditions for the primary stage of the synthesis can now be roughly circumscribed. If contact with the catalyst is sufficiently intimate, an appreciable part of the co can be converted to organics in times of less than 1 second at $170-400^{\circ} \mathrm{C}(6,8)$. Yet the reaction time (prior to the loss of $\mathrm{H}_{2}$ ) cannot have been very long, otherwise heavier organics would have been converted to $\mathrm{CH}_{4}$ by reaction with excess $\mathrm{H}_{2}$. Our experiments indicate that reaction times as long as a few days at $200-250^{\circ} \mathrm{C}$ are still permissible.

In the light of our experiments, a simpler picture can now be presented for the formation of organic compounds in meteorites. During the formation of the solar system, local regions of the solar nebula were heated to temperatures of $1000-2000^{\circ} \mathrm{K}$. The heating may have been caused by flares such as those observed in $\mathrm{T}$ Tauri stars, or by some other catastrophic process. The gas was of cosmic composition, with carbon and 
hydrogen present mainly as $\mathrm{CO}$ and $\mathrm{H}_{2}$. The gas mixture cooled to $<400^{\circ} \mathrm{K}$ on a time scale of seconds to months. During the cooling stage, metal and silicate particles condensed, and began to catalyze the reaction between $\mathrm{CO}$ and $\mathrm{H}_{2}$. The primary product distribution contained aromatics as well as the entire n-alkane series. Small amounts of noble gases and other volatiles were trapped in the interior of mineral grains growing from the supersaturated gas phase. Less-volatile organics condensed on the surfaces of mineral grains, and became isolated from the noncondensable gases (chiefly $\mathrm{H}_{2}$ ) which were subsequently lost. The condensed organics had an $\mathrm{H} / \mathrm{C}$ ratio less than $2: 1$, and thus lay well within the asphalt region of the $\mathrm{C}-\mathrm{H}-\mathrm{O}$ phase diagram. Subsequent slight heating brought the mixture close to equilibrium, enhancing; methane and aromatics at the expense of alkanes.

A point in favor of the proposed scheme for the formation of organics is its exact correspondence with current models for the formation of the inorganic constituents of meteorites (4). Precisely the same sequence of events is called for: local heating events in the solar nebula; rapid cooling; metamorphic reheating. And these conditions in turn are provided by many modern theories on the origin of the solar system (18).

There is reason to believe that the formation of hydrocarbons by the Fischer-Tropsch reaction is a rather common 
process in the universe. It will happen whenever $\mathrm{CO}, \mathrm{H}_{2}$, and meteoritic dust cool on a rapid time scale. These conditions must have been satisfied many times during the history of the solar system (19). 


\section{BIBLIOGRAPHY}

1. M. H. Studier, R. Hayatsu, and E. Anders, Science 149, 1455, (1965).

2. M. O. Dayhoff, E. R. Lippincott, R. V. Eck, Science 146, 1461 (1964).

3. H. C. Lord, III, Icarus 4, 279 (1965). Arnold E. Bainbridge has kindly provided us with data for an even wider range of temperatures and pressures.

4. J. A. Wood, Icarus 2, 152 (1963).

5. J. H. Beynon, Mass Spectrometry and its Applications to Organic Chemistry (Elsevier, Amsterdam, 1960); F. W. McLafferty, Mass Spectrometry of Organic Ions (Academic Press, New York, 1963).

6. Robert B. Anderson, in Catalysis, IV. Hydrocarbon Synthesis, Hydrogenation, and Cyclization, P. H. Emmett, Ed., (Reinhold, New York, 1956).

7. M.P.E. Berthelot, Bull. Soc. Chim. 9, 458 (1868) and 10, 337 (1868); F. Fischer and H. Tropsch, Brennstoffchemie 9, 309, (1928). 


\section{BIBLIOGRAPHY CONT.}

8. Herman S. Seelig, and Herman I. Weck, U. S. Patent No. 2,727,055, (Dec. 13, 1955); Herman I. Weck, and Herman

S. Seelig, U. S. Patent, No. 2,678,961, (Oct. 30, 1956);

Herman S. Seelig, and Herman I. Weck, U.S. Patent, No. $2,815,357$, (Dec. 3, 1957).

9. M. H. Briggs and G. Mamikunian, Space Science Reviews 1, 647, (1963).

10. J. Oró, D. W. Nooner, A. Zlatkis, and S. A. Wikström, Paraffinic Hydrocarbons in the Orguei1, Murray, Mokoia, and other Meteorites, Preprint, October (1965).

11. B. Nagy, W. G. Meinschein, D. J. Hennessy, Annals of the New York Acad. of Sciences, 93, 25 (1961), and 108, 553 (1963).

12. W. G. Meinschein, Space Science Reviews 2, 653, (1963); G.

P. Vdovykin, Geokhimiya 4, 299 (1964).

13. W. G. Meinschein, Science 150, 379 (1965).

14. A. P. Vinogradov, G. P. Vdovykin, Geokhimiya, 843, (1964).

15. J. Oró, Origins of Prebiological Systems and of Their Molecular Matrices, (Academic Press, New York, 1965), pp. $137-171$.

16. R. B. King et al, J. Inorg. Nuc1. Chem, 16, 233, (1961); H. Zeiss, Ed., Organometallic Chemistry, (Reinhold, New York, 1960), p. 468. 


\section{BIBLIOGRAPHY CONT .}

G. Egloff, Reactions of Pure Hydrocarbons, (Reinhold, New York, 1937); S. Coffey, Rodd's Chemistry of Carbon Compounds Vol. IA, (Elsvier, Amsterdam 1964).

17. J. E. Lovelock, Life Detection by Gas Chromatography, Preprint, November (1965).

18. Robert Jastrow and A. G. W. Cameron, Ed., Origin of the Solar System, (Academic Press, New York 1963).

19. Detailed experimental data on which this paper is based will be reported elsewhere. A preliminary account of this work was presented at the Autumn Meeting of the National Acad. of Sciences, Seattle, Washington, Oct. 12, 1965. We thank Alberta Martin, Leon P. Moore, and Atsuko Oda for technical assistance. This work was supported in part by the U.S. Atomic Energy Comm. and by the Natl. Aeronaut. and Space Adm. Grant NsG-366. 


\section{FIGURE CAPTIONS}

Fig. 1. Fischer-Tropsch Reaction with Meteorite Catalyst. After removal of unreacted $\mathrm{CO}$ at $-190^{\circ} \mathrm{C}$, the reaction mixture was briefly heated to $200^{\circ} \mathrm{C}$ to decompose metal carbonyls. Reaction products were then recondensed at $-190^{\circ} \mathrm{C}$ into the bottom of a 1-meter capillary tube, and were fractionally distilled. Periodically, the distilling species were admitted to the mass spectrometer. Identifications were based on published fragmentation patterns (5).

Fig. 2. Polynuclear Aromatic Hydrocarbons Produced at $900^{\circ} \mathrm{C}$ Without Catalyst. Many of these compounds have also been detected in meteorites. Anthracene and phenanthrene could not be distinguished mass spectrometrically. Compounds of 4 or more rings were separated by alumina chromatography and identified by UV spectrophotometry. 
Hydrocarbons from Reaction of $\mathrm{CO}$ and $\mathrm{H}_{2}(\mathrm{I}: 1)$ ( $\mathrm{T}=300^{\circ} \mathrm{C}, t=19 \mathrm{hrs}$, Iron Meteorite Catalyst)
(1) n-alkanes
$\mathrm{C}_{1}-\mathrm{C}_{20}$ and higher

2 iso-alkanes*

3 n-alkenes $\mathrm{C}_{2}, \mathrm{C}_{3}, \mathrm{C}_{4}, \mathrm{C}_{5}^{*}$, and higher ${ }^{*}$

4 iso-alkenes $\mathrm{C}_{5}-\mathrm{C}_{8}$

(5) alkadienes $\mathrm{C}_{5}, \mathrm{C}_{6}, \mathrm{C}_{7}$ and $\mathrm{C}_{8}^{*}$

(2) alicyclics ${ }^{*}$

(7) oxygenated aliphatic compounds*

$8 \underbrace{*} \mathrm{OH}_{3}\left(\mathrm{CH}_{3}\right)_{2} \mathrm{O}_{3} \mathrm{CH}_{3})_{3}$

Q1. and higher*aromatics

$\begin{array}{lllll}\mathrm{Ni}(\mathrm{CO})_{4} & \mathrm{Fe}(\mathrm{CO})_{5} & \mathrm{H}_{2} \mathrm{O} & \mathrm{CO}_{2}\end{array}$

* Identification tentative

Fig. I 
Hydrocarbons from Pyrolysis of $\mathrm{CH}_{4}$ or $\mathrm{CH}_{4}-\mathrm{CO}-\mathrm{CO}_{2}$ mixtures of $900^{\circ} \mathrm{C}$ (2-39 hours)

$\begin{array}{llll}\mathrm{C}_{2} \mathrm{H}_{4} & \mathrm{C}_{3} \mathrm{H}_{6} & \mathrm{C}_{4} \mathrm{H}_{8}\end{array}$

(1) $\mathrm{G}^{\mathrm{CH}_{3}} \hat{\mathrm{C}}^{\mathrm{C}} \mathrm{CH}$<smiles>c1ccc2ccccc2c1</smiles><smiles>c1ccc2ccccc2c1</smiles><smiles>Cc1ccc2ccccc2c1</smiles><smiles>C1=CC2=CC3=C(CC=C3)C2=C1</smiles><smiles>C1=CC2c3ccccc3C2C1</smiles><smiles></smiles><smiles></smiles>

PYRENE<smiles></smiles>

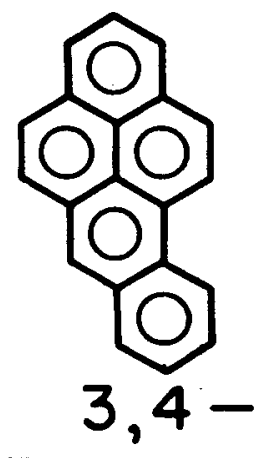

BENZOPYRENE

ÔO

CORONENE

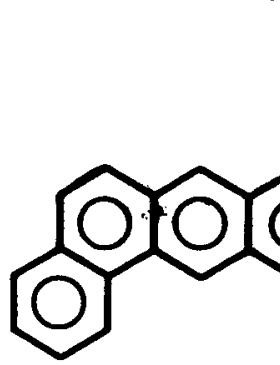

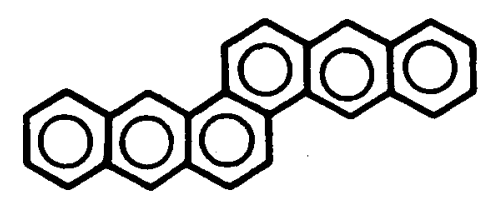

ANTHRACENO-(2.1: $1 . \overline{2})$

ANTHRACENE

Fig. 2 